\title{
A feasibility study of multiple micronutrient supplement for home fortification of foods among Orang Asli children in Negeri Sembilan, Malaysia
}

\author{
Nur Dayana Shaari, Zalilah Mohd Shariff', Gan Wan Ying \& Loh Su Peng \\ Department of Nutrition and Dietetics, Faculty of Medicine and Health Sciences, \\ Universiti Putra Malaysia, 43400 Serdang, Selangor, Malaysia
}

\begin{abstract}
Introduction: The prevalence of child undernutrition and micronutrient deficiencies are higher in the Orang Asli (OA) than the general Malaysian population. The World Health Organization recommends the use of multiple micronutrient supplement (MMS) that is a blend of micronutrients in powder form that can be sprinkled onto foods for home fortification to prevent undernutrition among children. This pilot study aimed to assess the feasibility of using MMS among OA children. Methods: A total of 25 OA children ( 14 boys and 11 girls) aged 6-31 months (mean \pm SD $=15.7 \pm 7.2$ months) in Negeri Sembilan were given three sachets of MMS weekly for 5 weeks. Caregivers were instructed to add MMS to three types of food from the same food group per week varying with a different food group weekly. Written instruction for using MMS in simple language was given prior to the supplementation. Caregivers were interviewed for information on socio-demographics, compliance, acceptance, preference and adverse effect of MMS. Results: A high level of compliance was observed (85\%). All caregivers reported that the instructions for use were easy to read. No noticeable changes to the foods mixed with MMS were observed and no adverse effects were reported. Conclusion: This study demonstrated feasibility of the use of MMS for future trials among OA children. The easy to read information that comes with the MMS, frequent monitoring of MMS use and support to caregivers were required to ensure compliance. Cultural feeding practices and financial constraints may limit the types of food that can be mixed with MMS.
\end{abstract}

Keywords: Multiple micronutrients supplement, feasibility study, Orang Asli children, micronutrient powder, home food fortification

\section{INTRODUCTION}

It is estimated that there are more than 370 million indigenous people residing in 70 countries worldwide, representing $5 \%$ of the world's population (IWGIA, 2018). They live predominantly in remote and rural areas, although minority now live in urban areas. The indigenous people generally have high rates of poverty, low education levels, high food insecurity and less access to health services as compared to the general population (Leite et al., 2013). Their morbidity rates are also higher. The prevalence of tuberculosis among indigenous population in Bolivia was 5 to 8 times

\footnotetext{
*Corresponding author: Zalilah Mohd Shariff

Department of Nutrition and Dietetics, Faculty of Medicine and Health Sciences,

Universiti Putra Malaysia, 43400 Serdang, Selangor, Malaysia

Tel: (6)03-8947 2605; Fax: (6)03-8947 2472; Email: zalilahms@upm.edu.my

doi: https://doi.org/10.31246/mjn-2019-0008
} 
higher compared to non-indigenous population, while gastrointestinal diseases were the main cause of death for children younger than 5 years of age (Montenegro \& Stephens, 2006). The same report showed that in 2003, the national infant mortality rates in Brazil, Colombia and Mexico were 31, 19 and 40 per 1000 infants, whereas it was 106, 111 and 81 per 1000 infants, for the respective indigenous communities. The prevalence of underweight, stunting and wasting among indigenous children in India were $55 \%, 54 \%$ and $28 \%$ compared to the national level of $43 \%, 48 \%$ and $20 \%$, respectively (IIPS \& Macro International, 2007). In Australia, 14\%, $11 \%$ and 10\% of indigenous children under 5 years were underweight, stunted, and had wasting, respectively (Northern Territory Department of Health and Community Services, 2007).

In Malaysia, the indigenous people constitute about $13.8 \%$ of the total population of 31 million (IWGIA, 2018). Of this, The Orang Asli (OA) who are the indigenous people of Peninsular Malaysia, represent $0.7 \%$ of the approximately 24.5 million population of Peninsular Malaysia. Generally, the $\mathrm{OA}$ are of low socio-economic status and have poor health and nutritional status (Zalilah \& Tham, 2002; Chua et al., 2012). In Malaysia, the prevalence of child undernutrition and micronutrient deficiencies are also much higher in the OA than the general population. The national prevalence of underweight, stunting, wasting and anaemia among children under 5 were $12.4 \%, 17.7 \%$, $8.0 \%$ and $32.0 \%$ respectively (IPH, 2015; WHO, 2015). Studies published since the 1980's on the nutritional status of OA children have consistently reported high prevalence of underweight (40$60 \%)$, stunting (50-60\%), wasting (7$15 \%)$ and anaemia among 2-15 years old (41.5\%) (Zalilah \& Tham, 2002; Nor
Aini et al., 2007; Chua et al., 2012; Oui \& Razalee, 2015).

Many strategies such as food fortification and supplementation have been implemented in population-level programmes to prevent undernutrition and micronutrient deficiencies in developing countries (WHO \& FAO, 2006). Although food fortification can improve micronutrient status with a reasonable cost (WHO \& FAO, 2006), fortified foods require well-absorbed fortificants that do not change the sensory properties of foods and need to be consumed adequately. While food supplementation can supply nutrients quickly to deficient individuals, poor compliance to supplement dosing schedules and the side effects have been reported as the barriers to success (WHO \& FAO, 2006). Evaluation of feasible and acceptable strategies to deliver multiple micronutrients is, thus, a priority (WHO, 2011). The Nutrition Guidance Expert Advisory Group (WHO, 2011) recommends the use of multiplemicronutrient supplements (MMS) as home fortification of foods consumed by infants and children aged 6-59 months of age to prevent child undernutrition. MMS is a blend of micronutrients in powder form that can be sprinkled onto home-prepared foods and has been used in many intervention trials among children aged 6-59 months in developing countries such as Kenya, Indonesia and Iran (Samadpour et al., 2011; Inayati et al., 2012; Jaeggi et al., 2015).

Many factors have been found to be associated with the success of MMS programmes such as acceptance, compliance, preference, and adverse effects (De-Regil et al., 2011; Kanashiro et al., 2016). Acceptance and compliance can be enhanced by providing information on the use and storage of MMS that are clear, adequate and culturally appropriate (De Pee 
et al., 2007; Jefferds et al., 2010). A home visit is also important to ensure that correct information on the use of MMS is delivered to caregivers as confusion on the preparation, required consistency and optimum practices was common (Halati et al., 2013; Kanashiro et al., 2016). This study was undertaken to assess the feasibility in terms of compliance, parental acceptance, child preference and adverse effects of the use of MMS, for a randomised-controlled trial among OA young children in Selangor.

\section{MATERIALS AND METHODS}

\section{Ethical approval}

The study protocol was approved by the Ethics Committee for Research involving Human Subjects (JKEUPM) of Universiti Putra Malaysia (Project reference number: (FPSK-P077) 2017). Permission to conduct the study in OA communities was obtained from the Department of Orang Asli Development (JAKOA). Written informed consent to participate in the study was obtained from caregivers.

\section{Design and participants}

The study was conducted in the Orang Asli Temuan villages in Seremban and Port Dickson districts, in the state of Negeri Sembilan in Peninsular Malaysia. A list of 14 villages was obtained from the Department of Orang Asli Development (JAKOA, 2016). Two villages in the Seremban district (Kampung Jeram Kedah and Kampung Tekir) and one village in the Port Dickson district (Kampung Bukit Kepong) were randomly selected. The total number of households in these villages was 149 for Kampung Tekir, 145 for Kampung Jeram Kedah and 137 for Kampung Bukit Kepong.

Data collection was carried out from June until August 2017. Households with children aged 6-36 months were identified and invited to participate in this study. The children were recruited based on the selection criteria: (1) age of 6-36 months; (2) no history of chronic diseases e.g. failure to thrive and/or metabolic or endocrine disorders; (3) no history of congenital and/or acquired neurological condition; (4) not under treatment for communicable diseases such as tuberculosis and human immunodeficiency viruses (HIV). A total of 33 young children were screened for eligibility and from these, 25 children were selected based on the responses of their caregivers who consented to participate in the study.

\section{Test treatment, dose and mode of administration}

Children were paid weekly visits and given three sachets of MMS per week, each containing $1 \mathrm{~g}$ sachet, consisting of ten vitamins and five minerals (Table 1). The amount of each micronutrient provided by MMS was mostly $\geq 42 \%$ of the Malaysian Recommended Nutrient Intake, (RNI). This was adequate to meet the daily nutrient requirement of children in addition to nutrients provided by daily complementary foods (NCCFN, 2017). The MMS was manufactured by DSM Singapore Industrial Pte. Ltd. It was in powder form and consumed orally by being sprinkled onto foods that were prepared at home for the child, every other day for five weeks. Caregivers were instructed to mix the MMS in three different types of food from the same food group 3 days/week and different food groups in the five weeks (week one: rice, tubers and cereals; week two: fruits; week three: vegetables; week four: meat, poultry, fish and eggs; week five: milk, dairy products and other beverage e.g. formula milk/ chocolate malted/ malted beverage). Written instructions in simple language with visuals for using and storing the MMS were given to caregivers prior to the supplementation. 
Table 1. The composition of multiplemicronutrient supplement used in this study

\begin{tabular}{|c|c|c|}
\hline No. & Nutrient & $\begin{array}{c}\text { Amount } \\
\text { per } 1 \mathrm{~g} \text { sachet }\end{array}$ \\
\hline 1 & Vitamin A, $\mu g$ RE & 400 \\
\hline 2 & Vitamin $\mathrm{C}, \mathrm{mg}$ & 30 \\
\hline 3 & Vitamin D, $\mu \mathrm{g}$ & 5 \\
\hline 4 & Vitamin $\mathrm{E}, \mathrm{mg} \alpha-\mathrm{TE}$ & 5 \\
\hline 5 & Vitamin B1, mg & 0.5 \\
\hline 6 & Vitamin B2, mg & 0.5 \\
\hline 7 & Vitamin B6, mg & 0.5 \\
\hline 8 & Vitamin B12, $\mu \mathrm{g}$ & 0.9 \\
\hline 9 & Folic Acid, $\mu \mathrm{g}$ & 90 \\
\hline 10 & Niacin, mg & 6 \\
\hline 11 & Iron, mg & 10 \\
\hline 12 & Zinc, mg & 4.1 \\
\hline 13 & Copper, $\mu \mathrm{g}$ & 560 \\
\hline 14 & Iodine, $\mu \mathrm{g}$ & 90 \\
\hline 15 & Selenium, $\mu \mathrm{g}$ & 17 \\
\hline
\end{tabular}

Source: WHO, WFP, UNICEF (2007)

\section{Measurements}

Socio-demographic information such as household income, age of parents, their education and employment were obtained through face-to-face interview with caregivers using a pre-tested questionnaire and with the assistance of a local translator. The date of birth of the child was obtained from the birth certificate or child's health records. Data were collected prior to the supplementation.

Compliance, acceptance, child preferences and the adverse effects of MMS were assessed through a weekly face-to-face interview with caregivers. The caregivers were visited each week, and given three sachets of MMS for one week of supplementation. After a week, caregivers were required to return the empty sachets (including unused or half used) to the investigator. Compliance of MMS was measured by dividing the total number of empty sachets with a total number of distributed sachets. The acceptance of MMS by the caregivers was assessed based on the ease of reading instructions for use, ability to understand instructions for use, ease of mixing MMS with food and willingness to use MMS in the future. Changes in food taste, colour or odour, the child's appetite and acceptance of food mixed with MMS were assessed for child preference of MMS. Caregivers were also asked to report the types of food mixed with MMS in $3 \mathrm{~d} /$ week. Any adverse effect such as cough, diarrhoea, bloody diarrhoea, difficulty in breathing and fever including the admission to hospital due to these conditions was also assessed during a weekly visit.

\section{Statistics}

Data were analysed using SPSS version 22.0 (SPSS Inc.) software. Descriptive statistics were expressed as mean and standard deviation for continuous variables and as frequencies for categorical variables. Data on compliance, acceptance, child preference and the adverse effect of MMS were expressed as frequencies and percentages.

\section{RESULTS}

The subjects in this study comprised 14 (56\%) boys and 11 (44\%) girls, with a mean age of $15.7 \pm 7.2$ months (Table 2 ). The mean monthly household income was RM864. Slightly more than half of the mothers (52\%) and fathers (56\%) had lower secondary education. The majority of the mothers were housewives $(80 \%)$ while the fathers were mostly selfemployed (88\%).

Table 3 shows the compliance, acceptance, child preferences and adverse effects of the five-weeks of MMS supplementation. A high level of $85 \%$ compliance was seen in this study. All caregivers reported that the instructions for use, were easy to read and understand, and 92\% reported a 
Table 2. Demographic and socio-economic characteristics $(\mathrm{N}=25)$

\begin{tabular}{|c|c|c|}
\hline Variables & $n(\%)$ & $M e a n \pm S D$ \\
\hline \multicolumn{3}{|l|}{ Gender of child } \\
\hline Male & $14(56)$ & \\
\hline Female & $11(44)$ & \\
\hline Age of child (month) & & $15.7 \pm 7.2$ \\
\hline \multicolumn{3}{|l|}{ Age groups of children } \\
\hline 6-8 months & $5(20)$ & \\
\hline 9-11 months & $4(16)$ & \\
\hline 12-14 months & $4(16)$ & \\
\hline 15-17 months & $1(4)$ & \\
\hline $18-20$ months & $5(20)$ & \\
\hline 21-24 months & $2(8)$ & \\
\hline 25-31 months & $4(16)$ & \\
\hline Household income (RM) & & $864 \pm 298$ \\
\hline Age of mother (years) & & $26.2 \pm 5.4$ \\
\hline Age of father (years) & & $28.4 \pm 5.9$ \\
\hline \multicolumn{3}{|l|}{ Education of mother } \\
\hline Primary level & $12(48)$ & \\
\hline Lower secondary level & $13(52)$ & \\
\hline \multicolumn{3}{|l|}{ Education of father } \\
\hline Primary level & $11(44)$ & \\
\hline Lower secondary level & $14(56)$ & \\
\hline \multicolumn{3}{|l|}{ Employment of mother } \\
\hline Housewife & $20(80)$ & \\
\hline Employed & $5(20)$ & \\
\hline \multicolumn{3}{|l|}{ Employment of father } \\
\hline Self-employed & $22(88)$ & \\
\hline Employed & $3(12)$ & \\
\hline
\end{tabular}

willingness to use MMS in the future. None of the caregivers reported changes in taste, colour, or odour of foods mixed with MMS. About 84\% caregivers reported no change in appetite of the children. All caregivers mixed MMS in rice porridge or rice from the first week one to the fifth. In week five, only two caregivers $(8 \%)$ reported they had mixed MMS in formula milk. No adverse effects were reported in this study.

\section{DISCUSSION}

Compliance among caregivers in this study was high. This was also observed in other trials using MMS in home-cooked food (Ogunlade et al., 2011; Albelbeisi et al., 2017). This could be attributed to the frequency of supplementation, where supplementation on alternate days is simpler to comply compared to other frequencies. A review by De-Regil et al. (2011) showed that children receiving intermittent iron supplementation had higher compliance compared to those receiving daily iron supplements. In this study, monitoring and support to caregivers were found to be necessary to ensure compliance. The caregivers were frequently reminded and encouraged to give the MMS as instructed during the weekly home visits by the investigator. This could explain the high level of compliance that we obtained (Lundeen et al., 2010; Halati et al., 2013). Pangaribuan et al. (2003) found that 
the understanding of the importance of supplementation of caregivers increased the compliance of vitamin A capsule supplementation among pre-school children in Indonesia.

Similar to previous studies (De Pee et al., 2007; Loechl et al., 2009; Jefferds et al., 2010; Albelbeisi et al., 2017), this study also found that MMS was well accepted by caregivers. Several factors which could explain the acceptance of MMS by caregivers have been identified in this study. First, the printed material provided to caregivers contained simple written and visual instructions for use of MMS. Several studies have shown that locally appropriate written and visual instructions that are tailored to suit the local cultural context increases acceptance of MMS by recipients (De Pee et al., 2007; Jefferds et al., 2010; Kanashiro et al., 2016). Second, the ease of use of MMS did not require caregivers to change their daily feeding practices as the MMS was given mixed in foods that were usually given to their children. It has been shown that MMS added into any semi-solid foods or commonly

Table 3. Compliance, acceptance, child preference and the adverse effect of five weeks MMS supplementation $(\mathrm{N}=25)$

\begin{tabular}{|c|c|c|}
\hline Variables & $n(\%)$ & Mean $\pm S D$ \\
\hline${ }^{\dagger}$ Compliance (\%) & & $85.0 \pm 25.5$ \\
\hline \multicolumn{3}{|l|}{ Acceptance } \\
\hline Easy to read instructions for use & $25(100)$ & \\
\hline Understand instructions for use & $25(100)$ & \\
\hline Easy to mix MMS with food & $25(100)$ & \\
\hline \multicolumn{3}{|l|}{ Willing to use in the future } \\
\hline Yes & $23(92)$ & \\
\hline No & $2(8)$ & \\
\hline \multicolumn{3}{|l|}{ Child preference } \\
\hline No change in taste of food & $25(100)$ & \\
\hline No change in colour of food & $25(100)$ & \\
\hline No change in odour of food & $25(100)$ & \\
\hline \multicolumn{3}{|l|}{ Change in child's appetite } \\
\hline No change & $21(84)$ & \\
\hline Increase appetite & $2(8)$ & \\
\hline Reduce appetite & $2(8)$ & \\
\hline \multicolumn{3}{|l|}{ Food mixed with MMS } \\
\hline Week 1: Rice, tubers and cereals & $25(100)$ & \\
\hline Week 2: Fruits & - & \\
\hline Week 3: Vegetables & - & \\
\hline Week 4: Meat, poultry, fish and eggs & - & \\
\hline Week 5: Milk, dairy products and other beverages & $2(8)$ & \\
\hline \multicolumn{3}{|l|}{ Adverse effect } \\
\hline Cough & $0(0)$ & \\
\hline Diarrhoea & $0(0)$ & \\
\hline Bloody diarrhoea & $0(0)$ & \\
\hline Difficulty in breathing & $0(0)$ & \\
\hline Fever & $0(0)$ & \\
\hline Admission to hospital due to these conditions & $0(0)$ & \\
\hline
\end{tabular}

${ }^{\dagger}$ Compliance rate is calculated by dividing a total number of consumed sachets with the total number of distributed sachets, then multiplying it with $100 \%$ 
taken food by children at home or at the point of use were well-accepted by caregivers (WHO 2011). Third, the home visits increased the acceptance as they provided opportunities for discussion between caregivers and investigator (Halati et al., 2013; Kanashiro et al., 2016).

Child acceptance of MMS in this study was good as all caregivers reported no noticeable changes in the taste, colour and odour of the foods mixed with MMS. This could be related to encapsulated ferrous fumarate with lipid (the source of iron in MMS) protects the interaction of iron with food and masks the metallic taste of the food upon adding MMS (Zlotkin et al., 2005; De Pee et al., 2007). There was no change in the appetite of the majority of the children. This could have been due to the short duration of the supplementation, as previous studies have shown that the appetite of the children increased in supplementation of longer duration such as two or six months (Loechl et al., 2009; Kanashiro et al., 2016).

In this study, caregivers were instructed to mix the MMS in five different food groups in each week. However, all caregivers only mixed MMS in rice or rice porridge from week one to week five as foods from other food groups were not affordable for them. Caregivers frequently feed their children with plain rice or porridge with a bit of salt and occasionally with a small quantity of fish. Several studies on dietary intake of OA children also reported that rice is the most frequently consumed food with limited intakes of fruits, milk and dairy products (Zalilah \& Tham, 2002; Chua et al., 2012). Low dietary diversity in OA children could be due to the limited household income as well as cultural feeding practices. Such low food variety was also observed in the diets of OA adults (Haemamalar, Zalilah \& Neng Azhanie, 2010). In generally, the diets of poor people are often monotonous and based on cereals, roots and tubers. Micronutrient-rich foods such as meat, fish, chicken, eggs, milk and dairy products are usually consumed only in small amounts (WHO \& FAO, 2006).

Only two caregivers reported that they mixed MMS with formula milk. Other caregivers who did not mix MMS with formula milk or other beverages reported that their children were still fully breastfeeding, or not taking formula milk or malted beverages. The children usually consumed tea or coffee, neither of which is recommended for mixing with MMS. The low intakes of milk and dairy products among the children could be because of the higher price of formula milk as compared to tea or coffee. Giving tea or coffee to the children was easier for parents as these beverages were routinely prepared for other family members. Chua et al. (2012) also found that OA children did not commonly take milk or malted beverages and about $69 \%$ of them took tea or coffee in their daily diets. The present study reported no adverse effect of MMS use and this finding was in line with previous studies (Samadpour et al., 2011; Inayati et al., 2012; Albelbeisi et al., 2017).

This study was not without limitations. Low variety of foods in the diets of the children may have contributed to the limitation of assessing acceptance and preference of MMS when combined to foods. In addition, the short duration of MMS supplementation could be a limiting factor in this study.

\section{CONCLUSION}

This study found that simple and easy to read information on MMS, frequent visits and communication to monitor MMS use and support to caregivers were essential to ensure compliance and acceptance of MMS. Cultural feeding practices, education level and knowledge 
of nutrition among the OA community, as well as financial constraints should be considered when designing an intervention. This study demonstrates the feasibility of using MMS for future trials among OA young children (6-24 months) to prevent undernutrition and anaemia.

\section{Acknowledgements}

This study was supported by a grant from Universiti Putra Malaysia (GP-IPS/2016/9514200). The MMS was sponsored by the DSM Nutritional Products Asia Pacific. The authors would like to thank the Department of Orang Asli Development (JAKOA) and study participants for their contributions to this study.

\section{Authors' contributions}

NDS, designed the study, collected and analysed the data and prepared the manuscript; ZMS, conceptualized and designed the study, supervised the project, reviewed and finalized the manuscript; GWY, supervised the project and reviewed the manuscript; Loh SP, supervised the project and reviewed the manuscript.

\section{Conflict of interest}

The authors declare no conflict of interest.

\section{References}

Albelbeisi A, Mohd Shariff Z, Chan YM, Abdul Rahman H \& Abed Y (2017). Use of micronutrient powder in at-home foods for young children (6-18 months): A feasibility study. Pak J Nutr 16:372-377.

Chua EY, Zalilah MS, Chin YS \& Norhasmah S (2012). Dietary diversity is associated with nutritional status of Orang Asli children in Krau Wildlife Reserve, Pahang. Mal J Nutr 18(1):1-13.

De Pee S, Moench-Pfanner R, Martini E, Zlotkin SH, Darnton-Hill I \& Bloem MW (2007). Home fortification in emergency response and transition programming: Experiences in Aceh and Nias, Indonesia. Food and Nutrition Bulletin 28(2):189-197.

De-Regil LM, Jefferds MED, Sylvetsky AC \& Dowswell T (2011). Intermittent iron supplementation for improving nutrition and development in children under 12 years of age. Cochrane Database of Systematic Reviews. doi:10.1002/14651858.cd009085.pub2.
Haemamalar K, Zalilah MS \& Neng Azhanie A (2010). Nutritional status of Orang Asli (Che Wong Tribe) adults in Krau Wildlife Reserve, Pahang. Mal J Nutr 16(1):55-68.

Halati S, Van Hees J, Uprety S, Schapendonk E $\&$ De Pee S (2013). Micronutrient powder supplementation program for Bhutanese refugee children in Jhapa and Morang districts, Nepal; Home fortification in refugee camps. Home fortification with micronutrient powders joint publication by the World Food Programme, Sight and Life, CDC and Home Fortification Technical Advisory Group (HFTAG). Sight and Life, Switzerland.

Inayati DA, Scherbaum V, Purwestri RC, Wirawan NN, Suryantan J, Hartono S, Bloem MA, Pangaribuan RV, Biesalski HK, Hoffmann V \& Bellows AC (2012). Combined intensive nutrition education and micronutrient powder supplementation improved nutritional status of mildly wasted children on Nias Island, Indonesia. Asia Pac J ClinNutr 21(3):361-373.

International Institute for Population Sciences (IIPS) and Macro International (2007) National Family Health Survey (NFHS-3), 2005-06: India: Volume I. Mumbai: IIPS.

IPH (2015). National Health \& Morbidity Survey (NHMS) 2015. Vol II: Non-communicable diseases, risk factors and other health problems. Institute for Public Health (IPH), Ministry of Health Malaysia, Kuala Lumpur.

IWGIA (2018). The Indigenous World 2018. International Work Group for Indigenous Affairs, Denmark.

Jaeggi T, Moretti D, Kvalsvig J, Holding PA, Njenga J, Mwangi A, Chhagan MK, Lacroix C \& Zimmermann MB (2015). In-home fortification with $2.5 \mathrm{mg}$ iron as NaFeEDTA does not reduce anaemia but increases weight gain: A randomised controlled trial in Kenyan infants. Maternal and Child Nutrition 11(Suppl. 4):151162.

JAKOA (2016). Population of Orang Asli in Negeri Sembilan. Jabatan Kemajuan Orang Asli (JAKOA), Negeri Sembilan.

Jefferds ME, Ogange L, Owuor M, Cruz K, Person B, Obure A, Suchdev PS \& Ruth LJ (2010). Formative research exploring acceptability, utilization, and promotion in order to develop a micronutrient powder (Sprinkles) intervention among Luo families in western Kenya. Food Nutr Bull. 31(Suppl. 2):S179-85. 
Kanashiro HC, Bartolini R, Abad M \& Arevalo V (2016). Promoting multi-micronutrient powders (MNP) in Peru: Acceptance by caregivers and role of health personnel. Maternal \& Child Nutrition 12: 152-163.

Leite MS, Cardoso AM, Coimbra CE Jr, Welch JR, Gugelmin SA, Lira PC, Horta BL, Santos RV \& Escobar AL (2013). Prevalence of anemia and associated factors among indigenous children in Brazil: results from the First National Survey of Indigenous People's Health and Nutrition. Nutrition Journal 12:69.

Loechl CU, Menon P, Arimond M, Ruel MT, Pelto G, Habicht JP \& Michaud L (2009). Using programme theory to assess the feasibility of delivering micronutrient sprinkles through a food-assisted maternal and child health and nutrition programme in rural Haiti. Maternal \& Child Nutrition 5(1):33-48. doi:10.1111/ j.17408709.2008.00154.x.

Lundeen E, Schueth T, Toktobaev N, Zlotkin S, Hyder SMZ \& Houser R (2010). Daily use of Sprinkles micronutrient powder for 2 months reduces anemia among children 6 to 36 months of age in the Kyrgyz Republic: A cluster-randomized trial. Food and Nutrition Bulletin 31(3): 446-460.

Montenegro RA \& Stephens C (2006). Indigenous health in Latin America and the Caribbean. Lancet 367(9525):1859-69.

NCCFN (2017). Recommended Nutrient Intakes for Malaysia. A Report of the Technical Working Group on Nutritional Guidelines. National Coordinating Committee on Food and Nutrition, Ministry of Health Malaysia, Putrajaya.

Nor Aini U, MS Hesham AM, Azlin M, Shaik A, Sa’iah A, Fatmah MS, Ismail MG, Ahmad Firdaus MS, Aish MY, Rozlida AR \& Norhayati M (2007). Serum iron status in Orang Asli children living in endemic areas of soil-transmitted helminths. Asia Pac J Clin Nutr 16(4):724-730.

Northern Territory Department of Health and Community Services (2007). Growth assessment and action program: GAA data collection April 2007. From http:/ / www.nt.gov. au/health/healthdev/gaa/gaa_report.pdf [Retrieved July 12 2016].

Ogunlade AO, Kruger HS, Jerling JC, Smuts CM, Covic N \& Hanekom SM (2011). Point-of-use micronutrient fortification: Lessons learned in implementing a preschool-based pilot trial in South Africa. Int J Food Sci Nutr 62(1):1-16.
Oui PG \& Razalee S (2015). Malnutrition and soil-transmitted helminthic infection among Orang Asli pre-school children in Gua Musang, Kelantan, Malaysia. AIP Conference Proceedings 1678 (050045). doi: 10.1063/1.4931324.

Pangaribuan R, Erhardt JG, Scherbaum V \& Biesalski HK (2003). Vitamin A capsule distribution to control vitamin A deficiency in Indonesia: effect of supplementation in pre-school children and compliance with the programme. Public Health Nutrition 6(2):209216.

Samadpour K, Long KZ, Hayatbakhsh R \& Marks GC (2011). Randomised comparison of the effects of Sprinkles and Foodlets with the currently recommended supplement (Drops) on micronutrient status and growth in Iranian children. European Journal of Clinical Nutrition 65:1287-1294.

WHO, WFP, UNICEF (2007). Joint statement. Preventing and controlling micronutrient deficiencies in populations affected by an emergency. From https://www.who.int/ nutrition/publications/micronutrients/WHO_ WFP_UNICEFstatement.pdf [Retrieved April 20 2016].

WHO (2011). Guideline: Use of multiple micronutrient powders for home fortification of foods consumed by infants and children 6-23 months of age. World Health Organization, Geneva.

WHO (2015). The global prevalence of anaemia in 2011. A guide for programme managers. World Health Organization, Geneva.

WHO \& FAO (2006). Guidelines on food fortification with micronutrients. World Health Organization, Geneva.

Zalilah MS \& Tham BL (2002). Food security and child nutritional status among Orang Asli (Temuan) households in Hulu Langat, Selangor. Med J Malaysia 57(1):36-50.

Zlotkin SH, Schauer C, Christofi des A, Sharieff W, Tondeur MC \& Ziauddin Hyder SM (2005). Micronutrient sprinkles to control childhood anaemia. PLoS Med 2(1):e1. 